Keywords:

Academia

Physician

Compensation

Recognition

Patient care

Clinical training

Corresponding Author: David M. Aronoff, MD 4618-C Med. Sci. BIdg. II II 50 W. Medical Center Dr. Ann Arbor, MI 48109-5623 Tel: $734-647-1786$

Fax: 734-763-4168

Email: daronoff@umich.edu

Received: August 4, 2009

Accepted: August 12, 2009

doi: $10.3121 / \mathrm{cmr} .2009 .878$

\section{And Then There Were None:
The Consequences of Academia Losing \\ And Then There Were None:
The Consequences of Academia Losing Clinically Excellent Physicians (1)}

David M. Aronoff, MD

$\mathrm{D}$

octors are not equal. Despite the homogenizing efforts of clinical care pathways, practice guidelines and pay-for-performance measures, some physicians outperform their peers. Along with providing clinical patient care, academic medical center physicians educate the next generation of doctors and create new knowledge through basic and clinical investigation. While many physicians are excellent at one of these functions, fewer are excellent at two, and even fewer at all three. In fact, the academic "triple threat" appears to be a dying breed. ${ }^{1}$ Although excellence in medicine is not ubiquitous, it is an important goal; lives depend on it. It is paramount that academic medical centers strive for excellence in clinical care, biomedical research and medical education.

Adisturbing trend has been the loss of clinically excellent physicians from academic medical centers. ${ }^{2}$ These physicians (sometimes called clinician-educators) excel in the provision of patient care and medical education. Their strengths lie in several domains including diagnostic acumen, knowledge, communication and interpersonal skills, professionalism and humanism, skillful negotiation of the health care system, taking a scholarly approach to clinical practice, and having passion for clinical medicine. ${ }^{3}$

Not only are excellent clinicians leaving academia, the timing of this exodus could not be worse, as there are reasonable arguments to be made that the quality of training for clinicians is, in general, suffering as training programs try to find a balance among reduced work hours, greater time off, and reduced contact time with excellent clinical faculty. ${ }^{4}$ The reasons for the erosion in the numbers of clinician-educators are complex. A recent survey study at a single academic medical center found several predictors of "serious intent" to leave academic medicine that included quality of life issues (eg, difficulty balancing family and career responsibilities); concerns that excellence in teaching and clinical service was not adequately recognized; poor fostering of career development; and perceived problems in institutional support. ${ }^{2}$ That report did not examine whether financial concerns influence the decision of academic physicians to leave for private sector careers. ${ }^{2}$ Academic medical centers must battle to retain faculty in light of the substantial educational debt burden carried by many new doctors and the often sizeable discrepancy in salary favoring private practice jobs. .5 Interventions are needed that address these sources of academic physician discontent. 
The consequences of institutions failing to recognize and reward clinical excellence have received less attention than the reasons why physicians abandon the academic milieu. In this issue of Clinical Medicine \& Research, Durso et $\mathrm{al}^{7}$ set out to more clearly delineate the implications of academic medicine's failure to recognize clinical excellence. This is an interesting, timely and informative study conducted by a group of investigators that has published several investigations into the motivations of academic clinician-educators and their professional development. . $^{3,8-12}$ The authors conducted in-depth interviews with 24 clinically excellent physicians (defined as such by their department chairs) from diverse specialties at leading academic institutions (as defined by U.S. News and World Report). Using transcripts from these interviews, the authors identified five concepts that consistently emerged as potential implications of a failure to recognize clinically excellent doctors at academic medical centers: low morale and prestige, less than excellent patient care, loss of talented clinicians, a lack of commitment to improve patient care systems, and fewer excellent clinical role models. These results should not be surprising. Failing to recognize the value of any member of an organization can erode morale, commitment and job performance, resulting in the eventual exodus of the undervalued member.

While the results of this study are not unexpected, they underscore an important challenge to academic medical centers - retaining valuable faculty members. How to fix this problem depends in part on how we recognize clinical excellence, which itself hinges on the definition of "recognize". Durso et $\mathrm{al}^{7}$ suggest that it is academic promotion (particularly to tenure) that primarily recognizes clinical excellence. They further note that the pathways to promotion within academia are more concretely defined for researchers (both clinical and basic) than for clinicians, impeding promotion for the latter cohort. However, it is not entirely clear that a lack of tenure for clinical faculty, or a lack of concrete goals for promotion, are nearly as culpable for prying clinicians from academia as inadequate financial reimbursement. Durso et $\mathrm{al}^{7}$ separate the financial remuneration of medical faculty from the "recognition" of clinical excellence noting, "Among other factors including the differential in income potential between academia and the private sector, inadequate recognition and reward systems may be driving physicians that are deeply committed to clinical work away from academic medical centers."7 However, money is an important extrinsic reward that can be used to recognize excellence in clinician-educators. As Durso et al note, academic medical centers lose talented physicians because "they soon come to realize that their talents will be more appreciated and respected in non-academic settings." 7 Since promotion to tenure does not often exist in private practice, it is conceivable that the increased income potential in this setting provides the sought-after recognition. Thus, in addition to recognizing excellent clinicians with promotion towards tenure, academic medical centers should consider financially incentivizing such excellence. The economic aspect of faculty retention may be the elephant in the room that deserves further attention in future studies.

It is important for the academic medical center readership of Clinical Medicine \& Research to consider the findings of Durso et $\mathrm{al}^{7}$ in the context of their own institution. Perhaps clinically excellent clinician-educators are being appropriately recognized at your medical center. If not, are consequences beginning to show? Efforts to standardize medical education and healthcare delivery will benefit when the common denominator across institutions and practitioners is excellence.

\section{References}

1. Hebert RS, Elasy TA, Canter JA. The Oslerian triple-threat: an endangered species? A survey of department of medicine chairs. Am J Med 2000;109:346-349.

2. Lowenstein SR, Fernandez G, Crane LA. Medical school faculty discontent: prevalence and predictors of intent to leave academic careers. BMC Med Educ 2007;7:37.

3. Christmas C, Kravet SJ, Durso SC, Wright SM. Clinical excellence in academia: perspectives from masterful academic clinicians. Mayo Clin Proc 2008;83:989-994.

4. Blanchard MS, Meltzer D, Polonsky KS. To nap or not to nap? Residents' work hours revisited. N Engl J Med 2009;360:2242-2244.

5. Fox M. Medical student indebtedness and the propensity to enter academic medicine. Health Econ 2003;12:101-112.

6. McDonald FS, West CP, Popkave C, Kolars JC. Educational debt and reported career plans among internal medicine residents. Ann Intern Med 2008;149:416-420.

7. Durso SC, Christmas C, Kravet SJ, Parsons G, Wright SM. Implications of academic medicine's failure to recognize clinical excellence. Clin Med Res 2009;7:127-133.

8. Wright SM, Kern DE, Kolodner K, Howard DM, Brancati FL. Attributes of excellent attending-physician role models. N Engl J Med 1998;339:1986-1993.

9. Atasoylu AA, Wright SM, Beasley BW, Cofrancesco J Jr, Macpherson DS, Partridge T, Thomas PA, Bass EB. Promotion criteria for clinician-educators. J Gen Intern Med 2003;18:711-716.

10. Beasley BW, Wright SM. Looking forward to promotion: characteristics of participants in the Prospective Study of Promotion in Academia. J Gen Intern Med 2003;18:705-710.

11. Beasley BW, Simon SD, Wright SM. A time to be promoted. The Prospective Study of Promotion in Academia (Prospective Study of Promotion in Academia). J Gen Intern Med 2006;21:123-129.

12. Ratanawongsa N, Howell EE, Wright SM. What motivates physicians throughout their careers in medicine? Compr Ther 2006;32:210-217.

\section{Author Affiliation}

David M. Aronoff, MD

Division of Infectious Diseases

Department of Internal Medicine

University of Michigan Health System

Ann Arbor, Michigan 